\title{
Tyrophagus putrescentiae predando insetos adultos de Aedes aegypti e Aedes albopictus em laboratório
}

\section{Tyrophagus putrescentiae predating adult insects of Aedes aegypti and Aedes albopictus in laboratory}

\author{
Lígia Leandro Nunes Serpaa, Marcia Regina Franzolin ${ }^{b}$, Darci Moraes Barros-Battestic e \\ Iná Kakitanic
}

aSuperintendência de Controle de Endemias. Taubaté, SP, Brasil. 'Instituto Butantan. São Paulo, SP, Brasil. ' ${ }^{2}$ epartamento de Epidemiologia. Núcleo de Pesquisa Taxonômica e Sistemática em Entomologia Médica. Faculdade de Saúde Pública. Universidade de São Paulo. São Paulo, SP, Brasil

\section{Descritores}

Comportamento predatório.

Tyrophagus putrescentiae. Aedes aegypti. Aedes albopictus.

\section{Keywords}

Predatory behavior. Tyrophagus putrescentiae. Aedes aegypti. Aedes albopictus.

\begin{abstract}
Resumo
O objetivo do estudo foi identificar ácaro infestando colônia de Aedes aegypti e Ae. albopictus, além da investigação de fonte de contaminação. A espécie de ácaro foi identificada pela montagem, em meio de Hoyer, entre lâmina e lamínula e observados em microscopia óptica, revelando tratar-se de Tyrophagus putrescentiae. Amostras de ração para peixe e de ração para coelho foram mantidas em estufa BOD a $27^{\circ} \mathrm{C}$ e $90 \%$ de umidade, por 21 dias, sendo examinadas semanalmente. A presença de $T$. putrescentiae foi somente observada em amostras de ração para coelho. Presumese que T. putrescentiae tenha sido introduzido nas colônias pela forésia em cobaias guinea-pigs, encontrando em ambiente de insetário na ocasião do evento $\left(28,7^{\circ} \mathrm{C}\right.$, $72 \%$ de umidade e fotoperíodo de $14 \mathrm{~L}: 10 \mathrm{E}$ horas) condições favoráveis para o seu desenvolvimento.
\end{abstract}

\begin{abstract}
The present study aimed at identifying a mite infesting a colony of Aedes aegypti and Ae. albopictus as well as investigating the source of infestation. The mite species was identified after it was mounted on slides in Hoyer's medium and examined under an optical microscope. It showed to be Tyrophagus putrescentiae. Fish and rabbit food samples were kept in an environmental chamber at $27^{\circ} \mathrm{C}$ and $90 \%$ humidity for 21 days and were weekly examined. The presence of $\mathrm{T}$. putrescentiae was only observed in rabbit food. It is assumed that $\mathrm{T}$. putrescentiae had been introduced into the colonies through phoresy among guinea pigs, which were kept at the time near the insectary under favorable conditions for their development $\left(28.7^{\circ} \mathrm{C}, 72 \%\right.$ humidity, photoperiod of 14L:10D hours).
\end{abstract}

\section{INTRODUÇÃO}

Os insetos hematófagos são veiculadores potenciais de vírus, bactérias, protozoários e helmintos patogênicos. ${ }^{1}$ Em saúde pública, é direcionada à família Culicidae, atenção especial dado seu envolvimento na transmissão de múltiplas infecções aos homens e aos animais domésticos. Aedes aegypti e Ae. albopictus são as duas únicas espécies de mosquitos pertencentes ao subgênero Stegomyia introduzidas até o momento na região Neotropical. A espécie Ae. aegypti, originária da África, reveste-se de grande im-
Correspondência para/ Correspondence to: Lígia Leandro Nunes Serpa

Praça Coronel Vitoriano, 23 Jardim Santa Clara 12020-020 Taubaté, SP, Brasil

E-mail: ligiaserp@sucen.sp.gov.br
Subvencionado pela Fundação de Amparo à Pesquisa do Estado de São Paulo (Fapesp - Processo n. 99/10517-1). Trabalho realizado no Laboratório de Culicídeos da Superintendência de Controle de Endemias, SR-3, Taubaté, SP, e Laboratórios de Parasitologia e de M icrobiologia do Instituto Butantan, São Paulo, SP. Recebido em 24/10/2003. Reapresentado em 15/4/2004. A provado em 31/5/2004. 


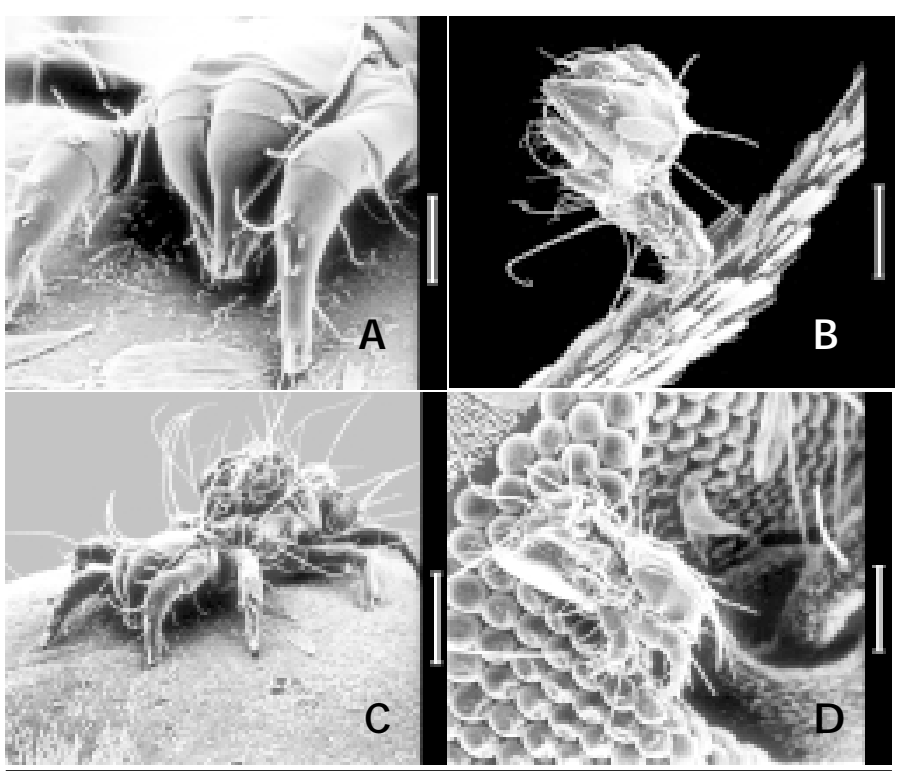

Figura - Tyrophagus putrescentiae (Acari: Astigmata) predando Aedes sp. (Diptera: Culicidae). A: ácaro no abdome de Ae. aegypti, barra 25 $\mu \mathrm{m}$, aumento $800 \mathrm{X}$. B: ácaro na perna de Ae. albopictus, barra $70 \mu \mathrm{m}$, aumento $300 \mathrm{X}$. C: ácaro sobre o escudo de Ae. albopictus, barra 70 $\mu \mathrm{m}$, aumento $300 \mathrm{X}$. D: ácaro no olho de Ae. albopictus, barra $40 \mu \mathrm{m}$, aumento $500 \mathrm{X}$.

portância epidemiológica na transmissão de dengue e febre amarela urbana. Já o Ae. albopictus é nativo do continente asiático, e embora apresente ameaça potencial na transmissão dessas e de outras arboviroses, até o momento não foi epidemiologicamente incriminado nas Américas. ${ }^{4}$

Diante da necessidade de estudos sobre esses mosquitos e a facilidade de sua manutenção em ambiente de laboratório, são mantidas colônias no Laboratório de Culicídeos da Superintendência de Controle de Endemias de Taubaté, SP. Durante o desenvolvimento de atividades de pesquisa, constatou-se número excessivo de alados mortos nas gaiolas de ambas as espécies. Quando observados em microscópio estereoscópio verificou-se a presença de formas jovens e adultas de ácaros da ordem Astigmata livres e fixados ao tórax, abdome e pernas.

Esses ácaros (Acari: Astigmata) encontrados em produtos armazenados e em poeira domiciliar possuem importância médico-veterinária. Se ingeridos, podem ocasionar intoxicação no homem e nos animais, como enterite aguda. São capazes de veicular bactérias, leveduras e fungos patogênicos através dos alimentos. Produzem alérgenos inalantes no ambiente que podem desencadear rinite alérgica e asma brônquica. Além disso, podem inocular produtos de suas glândulas salivares na epiderme humana, bem como na de animais, podendo causar graves dermatites. ${ }^{5}$

\section{MÉTODOS}

Exemplares de formas adultas de Ae. aegypti e Ae. albopictus saudáveis, moribundos e mortos foram retirados das colônias e submetidos a observações diárias em microscópio estereoscópio. Amostras de ácaros, juntamente com mosquitos, foram encaminhadas para identificação da espécie. Os ácaros foram montados em meio de Hoyer, entre lâmina e lamínula e observados em microscopia óptica. Alguns espécimes fixados aos insetos foram preparados para visualização em microscopia de varredura (Figura).

A presença de ácaros foi investigada em amostras de ração para peixe, utilizada na alimentação de larvas de Aedes e também em amostras de ração para coelho, utilizadas na alimentação das cobaias guineapigs. Essas foram introduzidas nas gaiolas, em ambiente de insetário, para o repasto sangüíneo das fêmeas de mosquitos. As amostras foram mantidas em estufa BOD a $27^{\circ} \mathrm{C}$ e $90 \%$ de umidade, por 21 dias, sendo examinadas semanalmente.

\section{RESU LTAD O}

As observações diárias possibilitaram verificar que os ácaros iniciavam a predação sobre os mosquitos adultos tornando-os primeiramente morimbundos e posteriormente levando-os à morte pela predação. Após o esvaziamento de todo o conteúdo interno dos mosquitos, o tórax era utilizado para albergar as fêmeas grávidas. Pôde ser constatada a presença de ovos e de larvas que, juntamente com as formas adultas exerciam a necrofagia do exoesqueleto do mosquito.

Os ácaros montados em meio de Hoyer foram identificados como Tyrophagus putrescentiae.

Das rações examinadas, somente a utilizada para coelho estava positiva para T. putrescentiae apresentando também uma grande quantidade de ovos de ácaros, detectada após o período de incubação.

\section{DISCUSSÃO}

A espécie T. putrescentiae é infestante em diversos alimentos, tais como: grãos, sementes, farelos, farinhas, rações para animais, produtos de salsicharia e queijos. Esse ácaro tem sido assinalado como praga 
em meios de cultura de fungos e em dietas de insetos de laboratórios, utilizando-se comumente de artrópodes, roedores, aves e outros animais, para se dispersarem no ambiente através da forésia. ${ }^{3}$ Presume-se que os ácaros estavam presentes na ração para coelhos e foram introduzidos nas colônias através de forésia em cobaias.

Este é o primeiro registro de $T$. putrescentiae predando o gênero Aedes uma vez que até o momento os relatos referem-se à presença de formas adultas e de ninfas hipopus deslocando-se somente na superfície corpórea dos insetos, bem como em suas dietas, ou alimentando-se de seus ovos e de restos orgânicos, mas não das formas adultas. ${ }^{2}$

O ambiente de insetário na ocasião do evento $\left(28,7^{\circ} \mathrm{C}, 72 \%\right.$ de umidade e fotoperíodo de $14 \mathrm{~L}: 10 \mathrm{E}$

\section{REFERÊNCIAS}

1. Carrera M. Insetos de interesse médico e veterinário. Curitiba: UFPR; 1991.

2. Fain A, Athias-Binche $F$, Carton Y. Histiostoma unidentatum n. sp. (Acari, Astigmata) associated with a fly Drosophila bipectinata originating from Thailand. Entomol 1993;63:71-6. horas) reuniu condições favoráveis para o desenvolvimento de T. putrescentiae.

Segundo Flechtmann ${ }^{3}$ (1986) as condições ideais para o desenvolvimento acariano são de $25^{\circ} \mathrm{C}$ com cerca de $20 \%$ do teor de água do produto e um limite mínimo de umidade relativa de $65 \%$. Esse autor sugere que alimentos e outros produtos sejam esterilizados a $60^{\circ} \mathrm{C}$ por 10 minutos para inviabilizar o ciclo biológico dos ácaros contaminantes. Diante disso, na criação de insetos, todos esses fatores devem ser considerados, bem como uma higienização constante.

\section{AG RADECIMENTOS}

Ao Professor Júlio Cesar Voltolini do Departamento de Biologia da Universidade de Taubaté pela revisão do trabalho quanto aos aspectos ecológicos.

3. Flechtmann $\mathrm{CHW}$. Ácaros em produtos armazenados e na poeira domiciliar. Piracicaba: Escola Superior de Agricultura Luiz de Queiroz; 1986.

4. Forattini OP. Culicidologia médica: identificação, biologia, epidemiologia. v. 2. São Paulo: Universidade de São Paulo; 2002.

5. Hughes AM. Mites of stored food and houses. $2^{\text {nd }}$ ed. London: HMSO ; 1976. 